\title{
Novel insights into transcriptional dysregulation in colorectal cancer
}

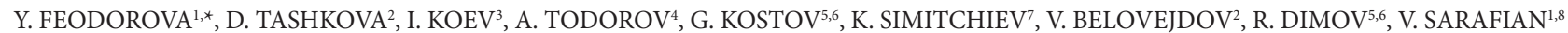

${ }^{1}$ Department of Medical Biology, Medical University of Plovdiv, Plovdiv, Bulgaria; ${ }^{2}$ Department of General and Clinical Pathology, Medical University of Plovdiv, Plovdiv, Bulgaria; ${ }^{3}$ Department of Neurosurgery, University Hospital „Pulmed“' Plovdiv, Bulgaria; ${ }^{4}$ Department of Propedeutics of Surgical Diseases, Medical University of Plovdiv, Plovdiv, Bulgaria; ${ }^{5}$ Department of Special Surgery, Medical University of Plovdiv, Plovdiv, Bulgaria; ${ }^{6}$ Department of Surgery, University Hospital "Kaspela", Plovdiv, Bulgaria; ${ }^{7}$ Department of Analytical Chemistry and Computer Chemistry, University of Plovdiv "Paisii Hilendarski", Plovdiv, Bulgaria; ${ }^{8}$ Technological Center for Emergency Medicine, Plovdiv, Bulgaria

${ }^{*}$ Correspondence: yanafeodorova@gmail.com

Received July 7, 2017 / Accepted September 13, 2017

\begin{abstract}
Colorectal cancer (CRC) is a leading cause of cancer-related mortality worldwide. Although CRC has been comprehensively characterized at the molecular level, the tumor heterogeneity hinders the identification of reliable diagnostic, prognostic and predictive biomarkers. Molecular stratification of CRC is based on prevalent gene mutations and transcription profiles but its significance for clinical practice remains obscure. Indeed, activating mutations in the genes KRAS, NRAS, and $B R A F$ are the only predictive biomarkers for anti-EGFR antibody therapy routinely tested in the clinic for advanced stages of CRC. Gene expression signatures are important for clarifying the molecular mechanisms of CRC development and progression, but only two such tests for predicting recurrence risk are commercially available. The aim of our study was to propose a diagnostic approach based on mutation and gene expression analysis that can be routinely applied in the clinic for defining the most appropriate treatment strategy for each patient. We used qPCR to determine the presence of KRAS mutations and measure the transcription levels of a panel of 26 genes in 24 CRC patients. Statistical analyses were applied to check for associations between clinicopathological and molecular parameters. Our results reveal novel data concerning CRC carcinogenesis: almost universal downregulation of EGFR; differential role of the pro-inflammatory cytokines TNF- $\alpha$ and IL-6; overexpression of the vitamin B12 transporter transcobalamin 1; tumor-suppressor function of SETD2, CA7, and GUCA2B. The practical application of these findings has yet to be clarified.
\end{abstract}

Key words: CRC, gene expression, GUCA2B, KRAS

Colorectal cancer (CRC) is the third most frequent cause of cancer-related death worldwide $[1,2]$. The improved surgical techniques and the introduction of more effective therapies has led to an incredible decline in CRC incidence and mortality among the population over 50 years of age in the last four decades [3]. Despite this positive trend, an alarming increase in incidence has been reported in younger people [4], necessitating the need for better prevention and early detection strategies. Important steps in this direction are the molecular characterization of CRC and the identification of suitable diagnostic, predictive and prognostic biomarkers. The first model of CRC tumorigenesis, describing it as a progressive accumulation of genetic and epigenetic events [5], was supplemented by more comprehensive description of the molecular events by the Cancer Genome Atlas Network in 2012 [6]. Thirty-two genes were found to be recurrently mutated with eight being most prevalent - APC, TP53, KRAS, PIK3CA, FBXW7, SMAD4,
TCF7L2 and NRAS. In addition, copy-number alterations leading to amplification of ERBB2 and IGF2 were found to be common events. Tumors were divided into two groups, hypermutated and non-hypermutated with different genetic mutations predominating in the different groups. Thereafter, numerous attempts have been made towards molecular stratification of CRC based on genetic variations and transcriptional profiling [7-13] with the goal of improving personalized treatment approaches [14]. This resulted in the development of a classification system including four consensus molecular subtype (CMS) groups [15], which best represent the heterogeneity of $\mathrm{CRC}$ at the gene expression level [16]. While CMS1 is characterized by microsatellite instability, hypermutation and mutations in MSH6, BRAF and PTEN, the other three subtypes are chromosomally unstable and enriched in mutations in APC, KRAS, TP53, SMAD4 and PIK3CA. CMS2 is marked by upregulation of WNT and MYC downstream targets, overexpression of 
EGFR, ERBB2, IGF2 etc., whereas activation of TGF- $\beta$ and proteins involved in extracellular matrix remodeling is a key feature of CMS4. KRAS mutations are dominant in CMS3 together with metabolic deregulation [16]. The CMS system was challenged in a recent publication by Isella et al. (2017) due to the large contribution of the tumor stromal content towards the transcriptional profiles utilized for the creation of the CMS subgroups. The authors of the study propose CRIS (CRC intrinsic subtypes)-based stratification and provide strong evidence that it can be exploited together with clinical and pathological parameters for better prognostic assessment of CRC [17]. In spite of the accumulating data regarding the molecular mechanisms of CRC and the efforts made towards molecular stratification of this cancer, little of this knowledge has found application in the clinics. Various biomarkers have been suggested for diagnosis, prediction and prognosis (reviewed in [18]), as well as for early CRC detection (reviewed in [19]) but only few of them are actually used in routine practice. Microsatellite instability (MSI) is associated with better prognosis and considering its prevalence in hypermutated cancers, it can be implied that high mutation rate may indicate better prognosis [6]. As far as molecular target therapy is concerned, only three negative biomarkers exist for advanced colorectal cancer drug treatment. Mutations in KRAS, NRAS, BRAF predict resistance to anti-EGFR antibodies [20]. Indeed, patients wild type for KRAS, NRAS, BRAF and PIK3CA, who represent 30\% of all cases, are most likely to benefit from this therapy [21] but acquired resistance due to EGFR mutations is a major problem [22-26]. No predictive biomarkers for anti-angiogenic treatment have been identified [16]. Gene expression profiling is indispensable for molecular subtyping of CRC but no established genomic signature has been found useful in clinical practice [27]. Gene expression signatures have been proposed for early detection based on blood samples $[28,29]$; for prognosis [30]; for estimating the risk of cancer occurrence [31]; for predicting response to chemotherapy in metastatic CRC [32] etc. Two such signatures, the Oncotype SX Colon Cancer Assay and the ColoPrint were validated as predictive markers for recurrence in stage II and III CRC but are not used everywhere. Isella et al. (2017) proposed reduction of the original CRIS 565 gene classifier to a set of 40 gene

Table 1. List of custom made primers used for qPCR.

\begin{tabular}{lll}
\hline Gene & Forward primer $\left[\mathbf{5}^{\prime} \rightarrow \mathbf{3}^{\prime}\right]$ & Reverse primer $\left[\mathbf{5}^{\prime} \rightarrow \mathbf{3}^{\prime}\right]$ \\
\hline YKL40 & GACCACAGGCCATCACAGTCC & TGTACCCACAGCATAGTCAGTGTT \\
$($ CHI3L1) & & \\
IL6 & ACGCAACCCACGTGTAACTGTC & ACAGCAACAAGCCCGTAGGAAC \\
MAPK1 & TCCCAAATGCTGACTCCAAAGC & TCCTCTTGTGTGGGTTGAATGTC \\
NFKB1 & CCTCCACAAGGCAGCAAATAGACG & AGCTGAGTTTGCGGAAGGATGTC \\
NRP1 & ACAGCAAACGCAAGGCGAAGTC & TGATGAATCGCGTGGAGAGAGC \\
PIK3CG & AAGTTTCAGGCAGCAGTGGAGAG & ACAAAGGTTGCCACACAGTAGCC \\
PTEN & TGTACTGGGCACATTCCTCCTC & TCAGAGTGTGGCAGAAGATAGTGG \\
GAPDH & AGGTCCACCACTGACACGTTG & AGCTGAACGGGAGCTCACT \\
\hline
\end{tabular}

pairs that can be used for clinical classification of individual patients, which would offer the greatest opportunity until now for personalized treatment. The aim of our study was to propose a diagnostic approach based on KRAS mutation and gene expression analysis that can be routinely applied in clinical practice for better evaluation of the patients and for appointing the most appropriate therapy. To this end, we measured the mRNA levels of an original constellation of 26 genes related to tumor growth, invasion and metastasis in CRC and correlated their expression to clinicopathological parameters, as well as to the KRAS mutation status of the patients. We did not find any significant associations between the expression levels of the chosen genes and tumor grade/stage or the presence of KRAS mutations. Interestingly, the only gene that shows any association to KRAS status is YKL40 [33]. Some of our results are novel and unexpected. First, SETD2, a histone methyltransferase, is ubiquitously downregulated in CRC, showing its significance as a tumorsuppressor gene also in this cancer type. Second, EGFR mRNA levels are decreased in a high proportion of cases, which can indicate reduced sensitivity to cetuximab even in $K R A S$ wild type patients. Third, we show that $T C N 1$, a vitamin B12 transporter, is highly overexpressed in CRC. Finally, two genes are universally lost in CRC - CA7 (carbonic anhydrase VII) and GUCA2B (uroguanylin), suggesting them as important tumor suppressor genes in CRC carcinogenesis.

\section{Patients and methods}

Patients and preparation of tissue samples. The study was approved by the Ethics Committee of the Medical University of Plovdiv, protocol \# R-1838/15-07-2013. Patients signed an informed consent in agreement with the requirements of the WMA Declaration of Helsinki. Twenty-four patients who underwent surgery in the years 2013 or 2014 at the two University hospitals "Kaspela" and "St. George" were selected. Tumor tissue and normal colonic mucosa distal to the tumor site were isolated by intraoperative resection and were stored in RNA later (Qiagen, Netherlands) at $-80^{\circ} \mathrm{C}$. In addition, formalin-fixed tumor tissue was embedded in paraffin for histological evaluation and DNA isolation.

Molecular analyses. DNA was isolated with the QIAamp DNA FFPE Tissue Kit (Qiagen, Hilden, Germany) and the KRAS mutation status was determined with the Amoy Dx KRAS Seven Mutations Detection Kit (Amoy Diagnostics, Haicang, Xiamen, China). RNA from normal and tumor tissue samples was isolated with the RNeasy Mini Kit (Qiagen) and converted to cDNA with the RT ${ }^{2}$ First Strand Kit (Qiagen). Gene expression of YKL40, IL6, MAPK1, NFKB1, NRP1, PIK3CG, and PTEN was measured by qPCR using the Maxima SYBR Green qPCR Master Mix (ThermoFisher Scientific, USA) and the primers listed in Table 1 (Integrated DNA Technologies, Leuven, Belgium) and Maxima SYBR Green/ROX qPCR Master Mix (Thermo Fisher Scientific, Waltham, MA, USA). The transcription levels of the other 19 
genes, AKT1, AXIN2, CA7, CD44, CTNNB1, EGFR, FGFR2, GPC1, GPC3, GUCA2B, KRAS, MACC1, MMP9, NOTUM, SETD2, SIRT3, TCN1, TNF and VEGF, were determined with customized RT ${ }^{2}$ Profiler PCR Array (SABiosciences, Qiagen). In all cases, samples were run in triplicates according to the MIQE guidelines. PCR reactions were carried out in Rotor Gene Q (Qiagen). The analysis was performed with the $\Delta \Delta \mathrm{C}_{\mathrm{T}}$ method individually for each patient. Expression of the gene in the normal tissue served as the calibrator and GAPDH was used as a reference gene. GAPDH was found to be stably expressed in normal colonic mucosa and tumor tissue and thus proved suitable for normalization of the gene expression data (Suppl. Figure 1).

Statistics. The non-parametric Mann-Whitney U test was applied to compare the values of a continuous variable in two independent groups. To determine the presence of correlation between two continuous variables the non-parametric coefficient Kendall's tau-b was calculated. The Log-rank test (Mantel-Cox) was used to identify the statistical difference between the survival of patients belonging to two different groups. Boxplot diagrams were used for graphical visualization of the continuous variables as well as for distinguishing outliers in the data series. They were created in BoxPlotR (http://shiny.chemgrid.org/boxplotr/). All statistical analyses were performed with SPSS software, version 17.0.

\section{Results}

Demographic and clinical parameters of the patients. The clinical parameters of the patients included in the study are shown in Table 2. The majority of patients were male; the mean age at the time of diagnosis was 73.9 years with no significant difference between both genders. The majority of tumors were localized in the rectum $(45.8 \%)$. In most patients, the tumors were staged as T2/T3 (70.8\%) and graded as G2 (87.5\%); lymph node engagement was observed in $25 \%$ of patients, whereas distant organ metastases were detected in $12.5 \%$. Different postoperative therapies were assigned to $62.5 \%$ of the patients, including PCT (33.3\%), adjuvant chemotherapy (16.7\%) or chemotherapy combined with radiation or immunotherapy $(12.5 \%)$. Within the timeframe of the study (2013-2017), 9 of the patients passed away and 15 are still under surveillance. The statistical analysis (Log-rank test) did not demonstrate any association between overall survival and T-stage (T1-4), age $(\geq /<70$ years $)$ and gender of the patients. The presence of local (lymph nodes) or distant metastases also did not influence the survival of the patients.

KRAS mutation status. Mutations in the genes KRAS, $N R A S$ and BRAF are the only predictive biomarkers in advanced $\mathrm{CRC}$, which determine resistance to targeted therapy with anti-EGFR antibodies. With qPCR as the method of choice in the current study, we detected mutations in the gene KRAS in 8 of the 24 patients, which is in agreement with the reported average prevalence of these mutations
Table 2. Clinical and demographic parameters of the patients.

\begin{tabular}{|c|c|c|c|}
\hline Parameter & & $\mathrm{n}$ & $\%$ \\
\hline \multirow{2}{*}{ Sex } & Female & 10 & 41.7 \\
\hline & Male & 14 & 58.3 \\
\hline \multirow{3}{*}{ Age } & $\leq 70$ years & 10 & 41.7 \\
\hline & $>70$ years & 14 & 58.3 \\
\hline & Women: $72.5 \pm 9.1$ & & \\
\hline \multirow[t]{2}{*}{ Mean age } & Men: $74.9 \pm 6.5$ & & \\
\hline & Total: $73.9 \pm 7.6$ & & \\
\hline \multirow{4}{*}{ Localization of the tumor } & Caecum & 3 & 12.5 \\
\hline & Transverse colon & 4 & 16.7 \\
\hline & Sigmoid colon & 6 & 25.0 \\
\hline & Rectum & 11 & 45.8 \\
\hline \multicolumn{4}{|l|}{ TNM stage } \\
\hline \multirow{4}{*}{ T stage } & $\mathrm{T} 1$ & 2 & 8.3 \\
\hline & $\mathrm{T} 2$ & 8 & 33.3 \\
\hline & $\mathrm{T} 3$ & 9 & 37.5 \\
\hline & $\mathrm{T} 4$ & 5 & 20.8 \\
\hline \multirow{3}{*}{$\begin{array}{l}\text { Lymph nodes }(\mathrm{N}) \text { and } \\
\text { metastases }(\mathrm{M})\end{array}$} & $\mathrm{T}(1-4) \mathrm{N} 0 \mathrm{M} 0$ & 15 & 62.5 \\
\hline & $\mathrm{T}(1-4) \mathrm{N}(1-\mathrm{x}) \mathrm{M} 0$ & 6 & 25.0 \\
\hline & $\mathrm{T}(1-4) \mathrm{NM} 1$ & 3 & 12.5 \\
\hline \multirow{3}{*}{ Cell differentiation } & G1 & 1 & 4.2 \\
\hline & G2 & 21 & 87.5 \\
\hline & G3 & 2 & 8.3 \\
\hline
\end{tabular}

in $30-40 \%$ of CRC patients. We did not observe any difference in the overall survival between the two groups - KRASmutant and KRAS-wild type.

Gene expression. We selected an original panel of 26 genes whose products participate in different signaling pathways or processes in CRC carcinogenesis (Figure 1). We used qPCR to measure the transcription levels of all genes and applied relative quantification individually for each patient using normal tissue as the calibrator. Despite the great heterogeneity among the studied samples, we grouped the genes in three different categories based on their differential expression in tumor versus normal tissue: (i) overexpressed genes (fold change $>2$, Figure 2A); (ii) genes with unchanged expression (fold change between 1 and 2, Figure 2B) and (iii) underexpressed genes (fold change $<1$, Figure 2C). The overexpressed genes were: NOTUM, TCN1, MACC1, YKL40, GPC3, AXIN2 and IL6 (Figure 2A, a1 insert). The most highly expressed gene in CRC tissue is NOTUM, a negative regulator of the Wnt signaling pathway, which was recently shown to be the only known extracellular deacylase that removes palmitoleate from Wnt proteins and inactivates them [34]. We recently demonstrated enhanced expression of NOTUM and deregulated expression of glypicans (GPC1 and GPC3) in CRC tissue [35] and confirmed some of these findings here. Genes that showed on average unchanged expression between the tumor and the normal tissue were: GPC1, CTNNB1, VEGF, CD44 and AKT1 


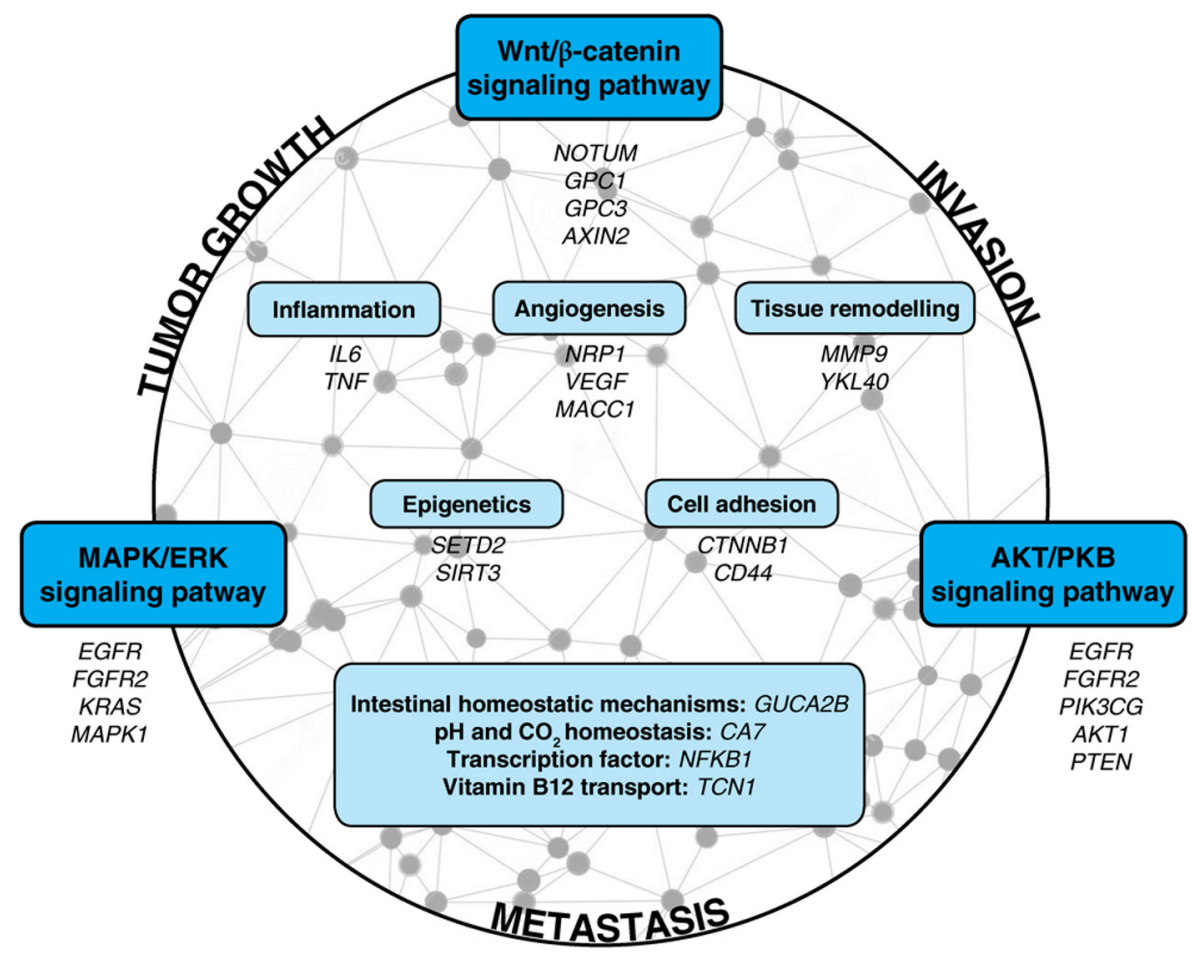

Figure 1. The panel of 26 genes whose transcription levels were measured in the study. The genes are roughly ordered according to the different signaling pathways they belong to or processes involved in CRC carcinogenesis. Receptor tyrosine kinases, e.g. EGFR and FGFR2 activate both MAPK/ERK and $\mathrm{AKT} / \mathrm{PKB}$ signaling. The circle is filled in with a pattern pointing to the fact that the products of these genes are all part of a network regulating tumor growth, invasion and metastasis.

(Figure 2B). The group of genes with decreased mRNA levels included: PTEN, SIRT3, MMP9, NRP1, NFKB1, TNF, MAPK1, SETD2, EGFR, KRAS, FGFR2, PIK3CG (Figure 2C) with $C A 7$ and GUCA2B showing the most prominent reduction in transcription (Figure 2, c1 insert). We applied statistical tests (Mann Whitney $\mathrm{U}$ ) to determine if any association exists between the expression levels of the studied genes and the KRAS mutation status of the patients, as well as various clinical and demographic parameters of the patients. This analysis showed that the transcription levels of the genes are not related to the presence of mutations in KRAS. The only exception is YKL40 whose expression is upregulated 5 times in the KRAS-wild type background [33]. Despite the lack of statistical significance, two other genes, SETD2 and MMP9, show a trend to be differentially regulated in the two patient groups. SETD2 expression, albeit generally low, is higher in patients bearing KRAS mutations ( $\mathrm{p}=0.098)$. The opposite is true for MMP9, which shows slightly elevated levels in KRASwild type patients than in those with mutations in the gene $(p=0.066)$. In addition, the Kendall tau test showed significant correlation between the expression of SETD2 and that of several other genes - EGFR, VEGF, CD44, PTEN, NRP1, YKL40, AKT1, FGFR2 and SIRT3. This result might point to the important role of SETD2 in CRC development/progression, as well as its possible function in the regulation of different cellular processes. The transcription levels of the 26 genes are affected neither by the age or the sex of the patients, nor by the localization, $\mathrm{T}$ stage or the grade of the tumor. There are two possible explanations for this phenomenon: the heterogeneity of CRC and the small sample size which do not allow very definitive interpretation of the results. The most extremely downregulated gene was GUCA2B. It was observed that the group with higher expression levels $(\geq$ mean $=0.05)$ had a worse overall survival than the group with lower expression levels $(<$ mean $=0.05)$ (Figure 3$)$.

Despite the difficulty in extrapolating the results from such a small patient cohort and making general conclusions, some of the findings of our study are novel and deserve attention. First, in $46 \%$ of patients the two pro-inflammatory cytokines, IL- 6 and TNF- $\alpha$, were not differentially expressed in the tumor compared to the normal tissue. In $50 \%$ of the cases, IL6 displayed moderately elevated levels (2-6 fold), whereas TNF was underexpressed. Second, we did not observe upregulation of EGFR in any of the studied patients. On the contrary, the gene was underexpressed in $71 \%$ of the cases and showed normal regulation in the rest. The same is true for the gene KRAS. Third, we obtained information about the expression of genes that have not been previously discussed in the context of CRC. Thus, SETD2 encoding a histone H3K36 methyltransferase is downregulated in $67 \%$ 


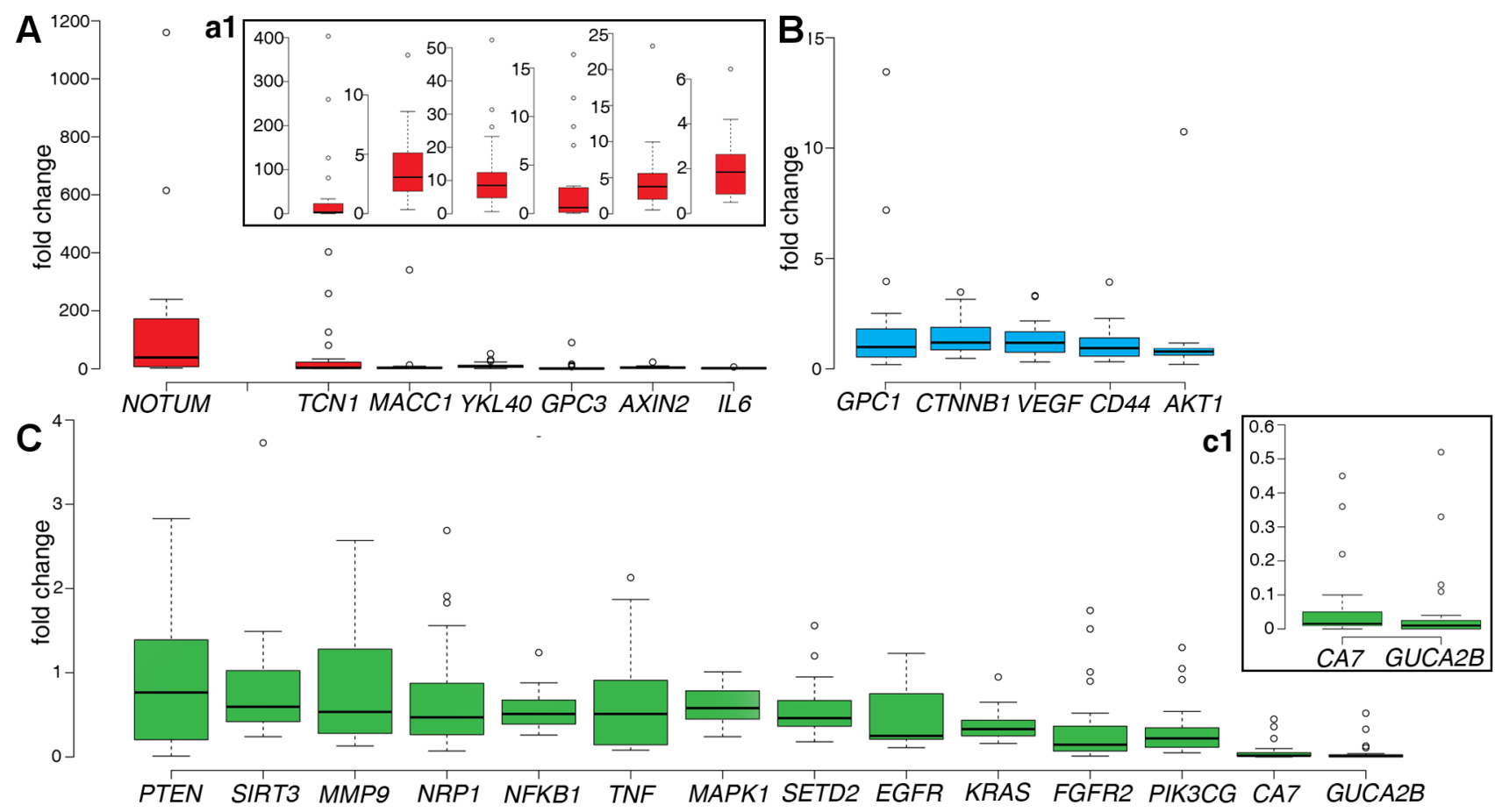

Figure 2. Transcription levels of the studied genes. A. Overexpressed genes (fold change $>2$ ). The most significantly upregulated gene is NOTUM. For clarity, the mRNA levels of TCN1, MACC1, YKL40, GPC3, AXIN2 and IL6 are shown on separate scales in a1. The genes which do not show significant changes in transcription levels in comparison to the normal mucosa are depicted in B. Downregulated genes (fold change $<1$ ) are depicted in C. CA7 and GUCA2B show the lowest levels of expression in CRC tissue (c1). Genes are classified as belonging to one of the three groups based on mean values of expression ( $n=24)$. Boxplots are created in BoxPlotR.

of our patients. TCN1, whose product transcobalamin is involved in vitamin B12 transport, is strongly overexpressed in the tumor tissue. Carbonic anhydrase VII (CA7) is a zinc metalloenzyme that catalyzes the reversible hydration of carbon dioxide and has multiple functions, among which is the regulation of the acid-base balance. Our results demonstrate extreme underexpression of the gene in $100 \%$ of the samples (Figure 2, cl insert). Furthermore, a correlation was found between the expression levels of this gene and GUCA2B, the product of which (uroguanylin) is thought to participate in the regulation of salt and water homeostasis in the intestine and kidneys.

\section{Discussion}

The results of our study should be interpreted with caution due to the small number of patients included in it. Though, they reveal several interesting aspects of CRC carcinogenesis, which we hereby discuss in more detail.

EGFR signaling. Blocking of EGFR signaling with antiEGFR monoclonal antibodies has emerged as a successful target therapy that has contributed to the increase in overall survival in CRC patients. Mutations in four genes are considered as negative predictive markers for this therapy - KRAS, NRAS, BRAF and PIK3CA, with quadruple wild type CRC

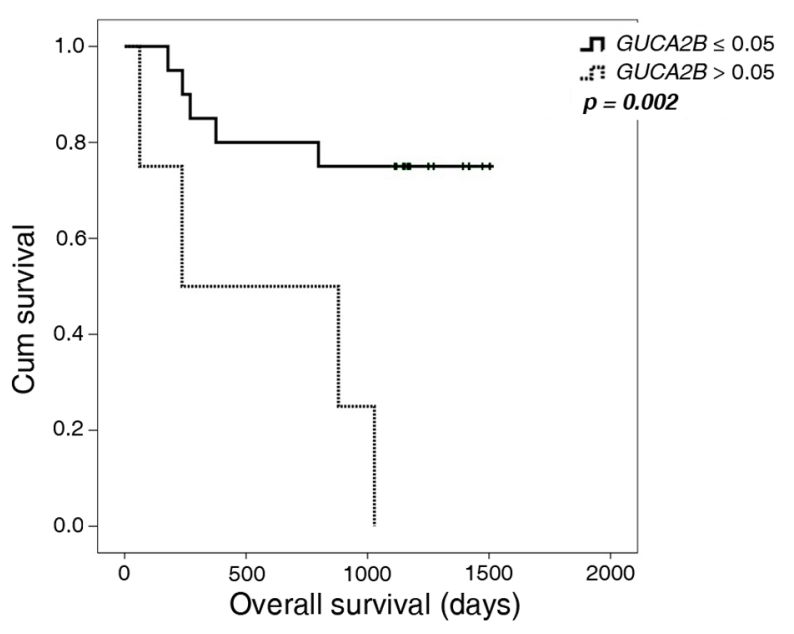

Figure 3. Kaplan-Meier estimates of overall survival in patients with colorectal cancer according to the expression level of GUCA2B.

patients benefiting most from cetuximab treatment [16]. EGFR overexpression is a hallmark of numerous human cancers, including CRC, and a few studies have looked into its effects on target therapy efficiency and prognosis. Some authors showed significant association between high EGFR expression and advanced tumor stage $[36,37]$, lymph node 
metastasis [38] and poorer overall survival [39], whereas others did not find it to be a useful prognostic marker $[37,40]$. Cetuximab was also shown to be more effective in patients with high protein expression of EGFR [41] or increased EGFR gene copy number [42]. Furthermore, mutations in the gene are associated with acquired resistance to anti-EGFR mAbs $[26,43]$. Surprisingly, our results showed moderately decreased mRNA levels of EGFR in $71 \%$ of the patients in the study but this low expression did not show any association with clinicopathological features. We can only speculate that a combination of KRAS mutations and EGFR downregulation might be indicative of poor response to anti-EGFR therapy.

Inflammation - IL-6 and TNF- $\boldsymbol{\alpha}$. Despite the tight link between chronic inflammation and different types of human cancers [44], studies concerning the levels of pro-inflammatory cytokines in the CRC tumor environment are contradictory. Furthermore, the role of pro-inflammatory cytokines for CRC progression from adenoma has been disputed [45]. Tumor Necrosis Factor Alpha (TNF- $\alpha$ ) activates the transcription factor $\mathrm{NF \kappa B}$, thus promoting proliferation and metastasis of tumor cells $[44,46]$. Several studies have demonstrated the link between increased TNF mRNA levels in the tumor tissue and advanced stages of CRC [47-49], suggesting that targeting TNF- $\alpha$ can be applied in treatment of CRC, especially when it has progressed from ulcerative colitis $[50,51]$. However, some authors report suppression of this cytokine in tumor, attributed to promoter-methylation of the gene [52]. Data on TNF- $\alpha$ serum levels are not less contradictory. While some authors claim significantly higher levels of the cytokine in serum of CRC patients and link this to the tumor development and progression [53], others do not detect it at all $[54,55]$. In contrast, studies investigating the role of IL- 6 in CRC are much more definitive. The elevated levels of the cytokine in CRC tissue [56] and serum [57] have been shown to be significantly associated with higher risk of relapse and survival of the patients. A monoclonal antibody binding to the IL- 6 receptor was shown effective in targeting colon cancer-stem like cells [58]. Despite the proposed downregulation of p53 by IL-6, which offers a link between inflammation and carcinogenesis [59], a meta-analysis by Zhou et al. (2014) did not find any significant association between IL- 6 and the risk of CRC [60]. Our results show slightly increased mRNA level of IL6 and decreased level of TNF in $50 \%$ of the patients. We did not find any association between the levels of these two cytokines and tumor stage or patients' age. The Kendal tau test showed significant correlation of IL6 expression with VEGF, NFKB1, PIK3CG, MAPK1, CTNNB1, AXIN2, GPC1, AKT1 and SIRT, suggesting a possible role of this pro-inflammatory cytokine in activating/regulating a variety of signaling pathways.

Histone modifications - SETD2. Proper functioning of the epigenetic regulatory machinery is crucial for maintaining genome integrity and cellular function. SETD2 is a single gene responsible for trimethylation of $\mathrm{H} 3 \mathrm{~K} 36$, a histone modification implicated in transcription elongation, splicing and DNA repair [61]. It has been also proposed that this methyltransferase interacts with $\mathrm{p} 53$ and selectively regulates the transcription of the transcription factors' target genes [62] but the significance of this interaction remains unknown. Inactivating mutations in the genes are most frequent in the clear cell renal cell cancer [61] but are also associated with high-grade gliomas [63]. Decreased mRNA levels of SETD2 have been associated with increasing tumor stage in breast cancer pointing to a tumor-suppressor role of this gene [64]. Our results of downregulated SETD2 expression in CRC tissue (67\% of patients) lead to a similar conclusion, although we did not find a link between the expression of this gene and the clinicopathological parameters. Although not significant, an association between KRAS mutation status and SETD2 expression was noted, the functional importance of which remains to be elucidated.

Vitamin B12 metabolism. Transcobalamin 1 (TCN1) is a member of the vitamin B12-binding protein family. It is expressed in various tissues and facilitates the transport of cobalamin into cells. The role of vitamin B12 metabolism has been studied in gastric cancer $[65,66]$, breast phyllodes cancer [67] and prostate cancer [68]. A recent meta-analysis of gene expression data obtained by microarrays showed that TNC1 is overexpressed in CRC tissue thus acting as an oncogene [69]. Although the role of vitamins has been extensively studied in gastrointestinal diseases (reviewed in [70]), the function of genetic variants and mRNA levels of TCN1 in CRC development and progression have not been thoroughly addressed. Our results demonstrate highly an increased transcription level of the gene in tumor tissue in $67 \%$ of CRC patients, in agreement with the results obtained from Chu et al. (2014).

Carbonic anhydrase VII and CRC. The meta-analysis of Chu et al. (2014) showed that CA7 and GUCA2B are also among the top eight differential genes in CRC, which act as tumor suppressors. Our results corroborated this view by showing decreased mRNA levels of both genes in 100\% of the patients. Actually, these two genes were the most prominently downregulated genes within the gene panel. Carbonic anhydrase VII (CA7) belongs to a group of metalloenzymes that catalyze the reversible hydration of carbon dioxide and are involved in many physiological and pathological processes. Inhibiting CAs represents a potential novel treatment for obesity, infections and cancer [71]. Expression of CA IX is highly elevated in many tumors as a consequence of hypoxia [71] and is linked to worse prognosis in CRC [72, 73]. Only few studies address the role of CA VII in cancer. Upregulation of the gene is associated with poor prognosis in astrocytoma patients [74], whereas decreased CA7 mRNA levels significantly correlated with poor differentiation, positive lymph node metastasis, advanced TNM stage and increased death rate in CRC patients [75]. Despite accumulating data, the differential role of CA isoenzymes in CRC remains to be elucidated. 
Guanylyl cyclase C signaling in CRC carcinogenesis. The gene GUCA2B codes for the hormone uroguanylin, one of the two ligands that activate guanylyl cyclase $\mathrm{C}$ (GUCY2C) signaling axis controlling fluid and electrolyte homeostasis [76]. Loss of uroguanylin (GUCA2B) and guanylin (GUCA2A) abrogates GUCY2C signaling, which is a universal feature of CRC [77, 78], strongly suggesting a role of $G U C Y 2 C$ as a tumor suppressor. In addition, GUCY2C signaling is downregulated in inflammatory bowel disease (IBD) $[79,80]$ providing a novel link between chronic inflammation and CRC carcinogenesis and suggesting a target for prevention of CRC by hormone replacement therapy [76]. The extreme downregulation of GUCA2B in all our patients conforms to previous studies underscoring the important role of uroguanylin-mediated signaling in CRC. Although ubiquitously lost, the levels of the gene are lower in patients with longer survival time. Also, GUCA2B expression showed no significant correlation with the expression of IL6 and TNF, which questions a direct link between GUCY2C signaling and inflammation. We have to note, however, that we did not study the expression of the other GUCY2C ligand, guanylin, and thus cannot make definitive conclusions since both hormones might have redundancy in function. In general, our results suggest that uroguanylin, as a secreted protein, can be indeed used as a biomarker for early detection of CRC [81], but hormone replacement therapy (linaclotide) should be applied rather for protection/prevention of inflammation-induced CRC than for treatment of advanced CRC.

Our study provides novel data on the transcriptional activity of a panel of 26 genes related to the tumor growth, invasion and metastasis in CRC. It offers new insights into a variety of signaling pathways involved in colorectal carcinogenesis, some of which are still waiting for their clinical implications.

Acknowledgements: The study is funded by grants from Medical University of Plovdiv ( $\mathrm{HO}-02 / 2013$ and $\mathrm{HO}-02 / 2015)$ and the Ministry of Education and Science, Bulgaria (DUNK 01-2/2009).

\section{References}

[1] FERLAY J, STELIAROVA-FOUCHER E, LORTET-TIEULENT J, ROSSO S, COEBERGH JW et al. Cancer incidence and mortality patterns in Europe: Estimates for 40 countries in 2012. Eur J Cancer 2013; 49: 1374-1403. https://doi. org/10.1016/j.ejca.2012.12.027

[2] SIEGEL R, DESANTIS C, JEMAL A. Colorectal cancer statistics, 2014. CA Cancer J Clin 2014; 64: 104-117. https://doi. org/10.3322/caac. 21220

[3] WELCH HG, ROBERTSON DJ. Colorectal Cancer on the Decline - Why Screening Can't Explain It All. N Engl J Med 2016; 374: 1605-1607. https://doi.org/10.1056/ NEJMp1600448
[4] SIEGEL RL, JEMAL A, WARD EM. Increase in incidence of colorectal cancer among young men and women in the United States. Cancer Epidemiol Biomarkers Prev 2009; 18: 1695-1698. https://doi.org/10.1158/1055-9965.EPI-09-0186

[5] FEARON ER, VOGELSTEIN B. A genetic model for colorectal tumorigenesis. Cell 1990; 61: 759-767.

[6] CANCER GENOM ATLAS. Comprehensive molecular characterization of human colon and rectal cancer. Nature 2012; 487: 330-337. https://doi.org/10.1038/nature11252

[7] SCHLICKER A, BERAN G, CHRESTA CM, MCWALTER G, PRITCHARD A et al. Subtypes of primary colorectal tumors correlate with response to targeted treatment in colorectal cell lines. BMC Med Genomics 2012; 5: 66. https:// doi.org/10.1186/1755-8794-5-66

[8] PEREZ-VILLAMIL B, ROMERA-LOPEZ A, HERNANDEZ-PRIETO S, LOPEZ-CAMPOS G, CALLES A et al. Colon cancer molecular subtypes identified by expression profiling and associated to stroma, mucinous type and different clinical behavior. BMC Cancer 2012; 12: 260. https:// doi.org/10.1186/1471-2407-12-260

[9] DE SOUSA E MELO F, WANG X, JANSEN M, FESSLER E, TRINH A et al. Poor-prognosis colon cancer is defined by a molecularly distinct subtype and develops from serrated precursor lesions. Nat Med 2013; 19: 614-618. https://doi. org/10.1038/nm.3174

[10] SADANANDAM A, LYSSIOTIS CA, HOMICSKO K, COLLISSON EA, GIBB WJ et al. A colorectal cancer classification system that associates cellular phenotype and responses to therapy. Nat Med 2013; 19: 619-625. https://doi. org/10.1038/nm.3175

[11] MARISA L, DE REYNIÈS A, DUVAL A, SELVES J, GAUB MP et al. Gene expression classification of colon cancer into molecular subtypes: characterization, validation, and prognostic value. PLoS Med 2013; 10: e1001453. https://doi. org/10.1371/journal.pmed.1001453

[12] BUDINSKA E, POPOVICI V, TEJPAR S, D'ARIO G, LAPIQUE $\mathrm{N}$ et al. Gene expression patterns unveil a new level of molecular heterogeneity in colorectal cancer. J Pathol 2013; 231: 63-76. https://doi.org/10.1002/path.4212

[13] ROEPMAN P, SCHLICKER A, TABERNERO J, MAJEWSKI I, TIAN $S$ et al. Colorectal cancer intrinsic subtypes predict chemotherapy benefit, deficient mismatch repair and epithelial-to-mesenchymal transition. Int J Cancer 2014; 134: 552-562. https://doi.org/10.1002/ijc.28387

[14] DIENSTMANN R, SALAZAR R, TABERNERO J. The evolution of our molecular understanding of colorectal cancer: what we are doing now, what the future holds, and how tumor profiling is just the beginning. Am Soc Clin Oncol Educ Book 2014; 91-99. https://doi.org/10.14694/EdBook_AM.2014.34.91

[15] GUINNEY J, DIENSTMANN R, WANG X, DE REYNIES A, SCHLICKER A et al. The consensus molecular subtypes of colorectal cancer. Nat Med 2015; 21: 1350-1356. https://doi. org/10.1038/nm.3967

[16] DIENSTMANN R, VERMEULEN L, GUINNEY J, KOPETZ $S$, TEJPAR $S$ et al. Consensus molecular subtypes and the evolution of precision medicine in colorectal cancer. Nat Rev Cancer 2017;17: 268. https://doi.org/10.1038/nrc.2017.24 
[17] ISELLA C, BRUNDU F, BELLOMO SE, GALIMI F, ZANELLA E et al. Selective analysis of cancer-cell intrinsic transcriptional traits defines novel clinically relevant subtypes of colorectal cancer. Nat Commun 2017; 8: 15107. https://doi. org/10.1038/ncomms15107

[18] REIMERS MS, ZEESTRATEN ECM, KUPPEN PJK, LIEFERS GJ, VAN DE VELDE CJH. Biomarkers in precision therapy in colorectal cancer. Gastroenterol Rep 2013; 1: 166183. https://doi.org/10.1093/gastro/got022

[19] VATANDOOST N, GHANBARI J, MOJAVER M, AVAN A, GHAYOUR-MOBARHAN $M$ et al. Early detection of colorectal cancer: from conventional methods to novel biomarkers. J Cancer Res Clin Oncol 2016; 142: 341-351. https://doi.org/10.1007/s00432-015-1928-Z

[20] SCUDELLARI M. Drug development: Mix and match. Nature 2015; 521: S12-14. https://doi.org/10.1038/521S12a

[21] DE ROOCK W, CLAES B, BERNASCONI D, DE SCHUTTER J, BIESMANS B et al. Effects of KRAS, BRAF, NRAS, and PIK3CA mutations on the efficacy of cetuximab plus chemotherapy in chemotherapy-refractory metastatic colorectal cancer: A retrospective consortium analysis. Lancet Oncol 2010; 11: 753-762. https://doi.org/10.1016/S14702045(10)70130-3

[22] ARENA S, BELLOSILLO B, SIRAVEGNA G, MARTINEZ A, CANADAS I et al. Emergence of multiple EGFR extracellular mutations during cetuximab treatment in colorectal cancer. Clin Cancer Res 2015; 21: 2157-2166. https://doi. org/10.1158/1078-0432.CCR-14-2821

[23] BETTEGOWDA C, SAUSEN M, LEARY RJ, KINDE I, WANG Y et al. Detection of circulating tumor DNA in earlyand late-stage human malignancies. Sci Transl Med 2014; 6: 224ra24. https://doi.org/10.1126/scitranslmed.3007094

[24] MORELLI MP, OVERMAN MJ, DASARI A, KAZMI SMA, MAZARD T et al. Characterizing the patterns of clonal selection in circulating tumor DNA from patients with colorectal cancer refractory to anti-EGFR treatment. Ann Oncol 2015; 26: 731-736. https://doi.org/10.1093/annonc/mdv005

[25] SIRAVEGNA G, MUSSOLIN B, BUSCARINO M, CORTI G, CASSINGENA A et al. Clonal evolution and resistance to EGFR blockade in the blood of colorectal cancer patients. Nat Med 2015; 21: 795-801. https://doi.org/10.1038/nm.3870

[26] BERTOTTI A, PAPP E, JONES S, ADLEFF V, ANAGNOSTOU $\mathrm{V}$ et al. The genomic landscape of response to EGFR blockade in colorectal cancer. Nature 2015; 526: 263-267. https://doi.org/10.1038/nature14969

[27] AKKAD J, BOCHUM S, MARTENS UM. Personalized treatment for colorectal cancer: novel developments and putative therapeutic strategies. Langenbecks Arch Surg 2015; 400: 129-143. https://doi.org/10.1007/s00423-015-1276-0

[28] XU Y, XU Q, YANG L, YE X, LIU F et al. Identification and validation of a blood-based 18-gene expression signature in colorectal cancer. Clin Cancer Res 2013; 19: 3039-3049. https://doi.org/10.1158/1078-0432.CCR-12-3851

[29] NICHITA C, CIARLONI L, MONNIER-BENOIT S, HOSSEINIAN S, DORTA G et al. A novel gene expression signature in peripheral blood mononuclear cells for early detection of colorectal cancer. Aliment Pharmacol Ther 2014; 39: 507-517. https://doi.org/10.1111/apt.12618
[30] NGUYEN MN, CHOI TG, NGUYEN DT, KIM J-H, JO YH et al. CRC-113 gene expression signature for predicting prognosis in patients with colorectal cancer. Oncotarget 2015; 6: 31674-3192. https://doi.org/10.18632/oncotarget.5183

[31] PESSON M, VOLANT A, UGUEN A, TRILLET K, DE LA GRANGE $P$ et al. A gene expression and pre-mRNA splicing signature that marks the adenoma-adenocarcinoma progression in colorectal cancer. PLoS One 2014; 9: e87761. https:// doi.org/10.1371/journal.pone.0087761

[32] ESTEVEZ-GARCIA P, RIVERA F, MOLINA-PINELO S, BENAVENT M, GOMEZ J et al. Gene expression profile predictive of response to chemotherapy in metastatic colorectal cancer. Oncotarget 2015; 6: 6151-6159. https://doi. org/10.18632/oncotarget.3152

[33] FEODOROVA Y, TASHKOVA D, SIMITCHIEV K, TODOROV A, KOSTOV G et al. Dependence of YKL-40 mRNA tissue levels on KRAS mutation status in colorectal cancer - preliminary results. Int J Surg Med 2015; 1: 43-47. https:// doi.org/10.5455/ijsm.20150723012230

[34] KAKUGAWA S, LANGTON PF, ZEBISCH M, HOWELL SA, CHANG TH et al. Notum deacylates Wnt proteins to suppress signalling activity. Nature 2015; 519: 187-192. https://doi.org/10.1038/nature14259

[35] DE ROBERTIS M, ARIGONI M, LOIACONO L, RICCARDO F, CALOGERO RA et al. Novel insights into Notum and glypicans regulation in colorectal cancer. Oncotarget 2015; 6: 41237-41257. https://doi.org/10.18632/oncotarget.5652

[36] GUO GF, CAI YC, ZHANG B, XU RH, QIU HJ et al. Overexpression of SGLT1 and EGFR in colorectal cancer showing a correlation with the prognosis. Med Oncol 2011; 28 Suppl 1: S197-203. https://doi.org/10.1007/s12032-010-9696-8

[37] SPANO JP, LAGORCE C, ATLAN D, MILANO G, DOMONT J et al. Impact of EGFR expression on colorectal cancer patient prognosis and survival. Ann Oncol 2005; 16: 102-108. https://doi.org/10.1093/annonc/mdi006

[38] LU Y, JINGYAN G, BAORONG S, PENG J, XU Y et al. Expression of EGFR, Her2 predict lymph node metastasis (LNM)-associated metastasis in colorectal cancer. Cancer Biomarkers 2012; 11: 219-126. https://doi.org/10.3233/ CBM-2012-00282

[39] HUANG CW, TSAI HL, CHEN YT, HUANG CM, MA CJ et al. The prognostic values of EGFR expression and KRAS mutation in patients with synchronous or metachronous metastatic colorectal cancer. BMC Cancer 2013; 13: 599. https:// doi.org/10.1186/1471-2407-13-599

[40] YAROM N, MARGINEAN C, MOYANA T, GORN-HONDERMANN I, BIRNBOIM HC et al. EGFR expression variance in paired colorectal cancer primary and metastatic tumors. Cancer Biol Ther 2010; 10: 416-421.

[41] LIU J, ZHOU Q, XU J, WANG J, ZHANG Y. Detection of EGFR expression in patients with colorectal cancer and the therapeutic effect of cetuximab. J BUON 2016; 21: 95-100.

[42] ÅlGARS A, AVORANTA T, OSTERLUND P, LINTUNEN $\mathrm{M}$, SUNDSTROM J et al. Heterogeneous EGFR gene copy number increase is common in colorectal cancer and defines response to anti-EGFR therapy. PLoS One 2014; 9: e99590. https://doi.org/10.1371/journal.pone.0099590 
[43] KHELWATTY SA, ESSAPEN S, SEDDON AM, FAN Z, MODJTAHEDI H. Acquired resistance to anti-EGFR mAb ICR62 in cancer cells is accompanied by an increased EGFR expression, HER-2/HER-3 signalling and sensitivity to pan HER blockers. Br J Cancer 2015; 113: 1010-1019. https://doi. org/10.1038/bjc.2015.319

[44] WANG K, KARIN M. Tumor-Elicited Inflammation and Colorectal Cancer. Adv Cancer Res 2015; 128: 173-196. https://doi.org/10.1016/bs.acr.2015.04.014

[45] HENRY CJ, SEDJO RL, ROZHOK A, SALSTROM J, AHNEN D et al. Lack of significant association between serum inflammatory cytokine profiles and the presence of colorectal adenoma. BMC Cancer 2015; 15: 123. https://doi. org/10.1186/s12885-015-1115-2

[46] BALKWILL F. TNF- $\alpha$ in promotion and progression of cancer. Cancer Metastasis Rev 2006; 25: 409-416. https://doi. org/10.1007/s10555-006-9005-3

[47] AL OBEED OA, ALKHAYAL KA, AL SHEIKH A, ZUBAIDI AM, VAALI-MOHAMMED MA et al. Increased expression of tumor necrosis factor- $\alpha$ is associated with advanced colorectal cancer stages. World J Gastroenterol 2014; 20: 18390-18396. https://doi.org/10.3748/wjg.v20.i48.18390

[48] BIGATTO V, DE BACCO F, CASANOVA E, REATO G, LANZETTI L et al. TNF-a promotes invasive growth through the MET signaling pathway. Mol Oncol 2015; 9: 377-388. https://doi.org/10.1016/j.molonc.2014.09.002

[49] GRIMM M, LAZARIOTOU M, KIRCHER S, HÖFELMAYR A, GERMER CT et al. Tumor necrosis factor-A is associated with positive lymph node status in patients with recurrence of colorectal cancer-indications for anti-TNF-A agents in cancer treatment. Cell Oncol (Dordr) 2011; 34: 315-326. https://doi.org/10.1007/s13402-011-0027-7

[50] POPIVANOVA BK, KITAMURA K, WU Y, KONDO T, KAGAYA T et al. Blocking TNF-alpha in mice reduces colorectal carcinogenesis associated with chronic colitis. J Clin Invest 2008; 118: 560-570. https://doi.org/10.1172/JCI32453

[51] CHANG LY, LIN YC, CHIANG JM, MAHALINGAM J, SU $\mathrm{SH}$ et al. Blockade of TNF- $\alpha$ signaling benefits cancer therapy by suppressing effector regulatory $\mathrm{T}$ cell expansion. Oncoimmunology 2015; 4: e1040215. https://doi.org/10.1080/2 162402X.2015.1040215

[52] GANAPATHI SK, BEGGS AD, HODGSON S V, KUMAR D. Expression and DNA methylation of TNF, IFNG and FOXP3 in colorectal cancer and their prognostic significance. $\mathrm{Br}$ J Cancer 2014; 111: 1581-1589. https://doi.org/10.1038/ bjc. 2014.477

[53] STANILOV N, MITEVA L, DOBREVA Z, STANILOVA S. Colorectal cancer severity and survival in correlation with tumournecrosisfactor-alpha.BiotechnolBiotechnolEquip 2014; 28: 911-917. https://doi.org/10.1080/13102818.2014.965047

[54] UEDA T, SHIMADA E, URAKAWA T. Serum levels of cytokines in patients with colorectal cancer: possible involvement of interleukin- 6 and interleukin- 8 in hematogenous metastasis. J Gastroenterol 1994; 29: 423-429.

[55] KIM YW, KIM SK, KIM CS, KIM IY, CHO MY et al. Association of serum and intratumoral cytokine profiles with tumor stage and neutrophil lymphocyte ratio in colorectal cancer. Anticancer Res 2014; 34: 3481-3487.
[56] OLSEN J, KIRKEBY LT, OLSEN J, EIHOLM S, JESS P et al. High interleukin-6 mRNA expression is a predictor of relapse in colon cancer. Anticancer Res 2015; 35: 2235-2240.

[57] LU CC, KUO HC, WANG FS, JOU MH, LEE KC et al. Upregulation of TLRs and IL-6 as a marker in human colorectal cancer. Int J Mol Sci 2014; 16: 159-177. https://doi. org/10.3390/ijms16010159

[58] YING J, TSUJII M, KONDO J, HAYASHI Y, KATO $\mathrm{M}$ et al. The effectiveness of an anti-human IL-6 receptor monoclonal antibody combined with chemotherapy to target colon cancer stem-like cells. Int J Oncol 2015; 46: 1551-1559. https://doi.org/10.3892/ijo.2015.2851

[59] BRIGHENTI E, CALABRESE C, LIGUORI G, GIANNONE FA, TRERE D et al. Interleukin 6 downregulates p53 expression and activity by stimulating ribosome biogenesis: a new pathway connecting inflammation to cancer. Oncogene 2014; 33: 4396-4406. https://doi.org/10.1038/onc.2014.1

[60] ZHOU B, SHU B, YANG J, LIU J, XI T et al. C-reactive protein, interleukin- 6 and the risk of colorectal cancer: a meta-analysis. Cancer Causes Control 2014; 25: 1397-1405. https://doi.org/10.1007/s10552-014-0445-8

[61] LI J, DUNS G, WESTERS H, SIJMONS R, VAN DEN BERG A et al. SETD2: an epigenetic modifier with tumor suppressor functionality. Oncotarget 2016; 7: 50719-50734. https:// doi.org/10.18632/oncotarget.9368

[62] XIE P, TIAN C, AN L, NIE J, LU K et al. Histone methyltransferase protein SETD2 interacts with p53 and selectively regulates its downstream genes. Cell Signal 2008; 20: 16711678. https://doi.org/10.1016/j.cellsig.2008.05.012

[63] FONTEBASSO AM, SCHWARTZENTRUBER J, KHUONG-QUANG DA, LIU XY, STURM D et al. Mutations in SETD2 and genes affecting histone H3K36 methylation targethemispherichigh-gradegliomas. Acta Neuropathol 2013; 125: 659-669. https://doi.org/10.1007/s00401-013-1095-8

[64] AL SARAKBI W, SASI W, JIANG WG, ROBERTS T, NEWBOLD RF et al. The mRNA expression of SETD2 in human breast cancer: correlation with clinico-pathological parameters. BMC Cancer 2009; 9: 290. https://doi.org/10.1186/14712407-9-290

[65] CLAERHOUT S, LIM JY, CHOI W, PARK YY, KIM K et al. Gene Expression Signature Analysis Identifies Vorinostat as a Candidate Therapy for Gastric Cancer. PLoS One 2011; 6: e24662. https://doi.org/10.1371/journal.pone.0024662

[66] ZHAO L, WEI Y, SONG A, LI Y. Association study between genome-wide significant variants of vitamin B12 metabolism and gastric cancer in a han Chinese population. IUBMB Life 2016; 68: 303-310. https://doi.org/10.1002/iub.1485

[67] CHONG LYZ, CHEOK PY, TAN WJ, THIKE AA, ALLEN G et al. Keratin 15, transcobalamin I and homeobox gene HoxB13 expression in breast phyllodes tumors: Novel markers in biological classification. Breast Cancer Res Treat 2012; 132: 143-151. https://doi.org/10.1007/s10549-011-1555-6

[68] COLLIN SM, METCALFE C, PALMER TM, REFSUM H, LEWIS SJ et al. The causal roles of vitamin B 12 and transcobalamin in prostate cancer: can Mendelian randomization analysis provide definitive answers? Int J Mol Epidemiol Genet 2011; 2: 316-327. 
[69] CHU CM, YAO CT, CHANG YT, CHOU HL, CHOU YC et al. Gene expression profiling of colorectal tumors and normal mucosa by microarrays meta-analysis using prediction analysis of microarray, artificial neural network, classification, and regression trees. Dis Markers 2014; 2014: 634123. https://doi.org/10.1155/2014/634123

[70] MASRI OA, CHALHOUB JM, SHARARA AI. Role of vitamins in gastrointestinal diseases. World J Gastroenterol 2015; 21: 5191-5209. https://doi.org/10.3748/wjg.v21.i17.5191

[71] SUPURAN CT. Carbonic anhydrases: novel therapeutic applications for inhibitors and activators. Nat Rev Drug Discov 2008; 7: 168-181. https://doi.org/10.1038/nrd2467

[72] KORKEILA E, TALVINEN K, JAAKKOLA PM, MINN H, SYRJANEN $\mathrm{K}$ et al. Expression of carbonic anhydrase IX suggests poor outcome in rectal cancer. Br J Cancer 2009; 100: 874-880. https://doi.org/10.1038/sj.bjc.6604949

[73] CLEVEN AHG, VAN ENGELAND M, WOUTERS BG, DE BRUINE AP. Stromal expression of hypoxia regulated proteins is an adverse prognostic factor in colorectal carcinomas. Cell Oncol 2007; 29: 229-240.

[74] BOOTORABI F, HAAPASALO J, SMITH E, HAAPASALO H, PARKKILA S. Carbonic anhydrase VII-a potential prognostic marker in gliomas. Health [Irvine Calif] 2011; 3: 6-12.

[75] YANG GZ, HU L, CAI J, CHEN HY, ZHANG Y et al. Prognostic value of carbonic anhydrase VII expression in colorectal carcinoma. BMC Cancer 2015; 15: 209. https:// doi.org/10.1186/s12885-015-1216-y
[76] PATTISON AM, MERLINO DJ, BLOMAIN ES, WALDMAN SA. Guanylyl cyclase C signaling axis and colon cancer prevention. World J Gastroenterol 2016; 22: 8070-8077. https://doi.org/10.3748/wjg.v22.i36.8070

[77] WILSON C, LIN JE, LI P, SNOOK AE, GONG J et al. The Paracrine Hormone for the GUCY2C Tumor Suppressor, Guanylin, Is Universally Lost in Colorectal Cancer. Cancer Epidemiol Biomarkers Prev 2014; 23: 2328-2337. https://doi. org/10.1158/1055-9965.EPI-14-0440

[78] COHEN MB, HAWKINS JA, WITTE DP. Guanylin mRNA expression in human intestine and colorectal adenocarcinoma. Lab Invest 1998; 78: 101-108.

[79] LAN D, NIU J, MIAO J, DONG X, WANG H et al. Expression of guanylate cyclase- $\mathrm{C}$, guanylin, and uroguanylin is downregulated proportionally to the ulcerative colitis disease activity index. Sci Rep 2016; 6: 25034. https://doi.org/10.1038/ srep25034

[80] BRENNA O, FURNES MW, MUNKVOLD B, KIDD M, SANDVIK AK et al. Cellular localization of guanylin and uroguanylin mRNAs in human and rat duodenal and colonic mucosa. Cell Tissue Res 2016; 365: 331-341. https://doi. org/10.1007/s00441-016-2393-y

[81] NAGARAJ SH, REVERTER A. A Boolean-based systems biology approach to predict novel genes associated with cancer: Application to colorectal cancer. BMC Syst Biol 2011; 5: 35. https://doi.org/10.1186/1752-0509-5-35 